\title{
Successful application of Eschscholzia californica to combat opioid addiction
}

\begin{abstract}
In the US today, a staggering 115 people die daily due to the tragedy of being addicted to opioids.

Some estimates are that this epidemic will cripple the economy with an 80-billion-dollar burden on taxpayers, who foot the bill for intervention, legal fees, and health for these individuals in the drug's insidious grip. ${ }^{2}$ The crisis has permeated everywhere in our society...even into small towns across America, and into my practice in rural CT.

In this editorial are two cases highlighting the power of botanical medicine, which assisted several patient's to beat this addiction.
\end{abstract}

Volume II Issue 4 - 2018

\author{
Eugene R Zampieron \\ University of Bridgeport College of Naturopathic Medicine, \\ USA
}

Correspondence: Eugene Zampieron, University of Bridgeport College of Naturopathic Medicine, 413 Grassy Hills Rd,Woodbury, CT 06798, USA, Tel (203) 2632970, Email drznaturally@gmail.com

Received: June 28, 2018 | Published: July 24, 2018

\section{Stopping narcotic addiction with California poppy tincture}

In 2002, a 34 y/o female amputated her finger in a large metal door Her surgical repair was successful, but she was plagued with severe neuropathic from the episode.

She was Prescribed Oxycodone (OxyContin, Roxicodone) by her surgeon. The pain continued to persist, and she was allowed to remain on the drug for 12 months time. Unfortunately, she became addicted and her social and emotional life became seriously affected.

The patient came to me (DrZ) at my clinic in Woodbury, CT, for help with this addiction, and to perhaps help with the chronic pain.

Previous to this, DrZ read a citation in Mills/Bone a reference by Fundythus et al. that plants with chelerythrine reduce morphine dependence in animals. ${ }^{3}$

California poppy(Eschscholzia californica) has Chelerythrine, amongst many alkaloids, and the Eclectic physicians (Felter, King Lloyd) at the turn of the last century used this plant when opium was indicated for pain but couldn't be tolerated, so the patient agreed to try this intervention.

DrZ attempted the intervention \& prescribed tincture of Eschscholzia 1:2 potency (where $2 \mathrm{ml}$ of tincture delivers 1gram of crude drug Eschscholzia); sig:1 tsp q $2 \mathrm{hr}$ waking On this protocol the patient was able to escape the addiction of oxycodone over a period of 1 month; the extract also helped chronic neuropathic pain as well.

\section{Weaned off of Low Dose Naltrexone (LDN) therapy with eschscholzia}

A patient at my clinic with chronic pain due to Rheumatoid arthritis, non responsive to many OTC drugs and even many botanicals, was placed on Low dose Naltrexone by her pain specialist. Feeling a dependency growing, she approached DrZ about how she felt.

I discussed with her many cases since 202 where I successfully wean patients off of opiods with California poppy tincture.

As with many of the cases, she too was weaned off of Low dose Naltrexone (LDN) therapy with Eschscholzia and achieved better analgesia than with LDN
The sig was Eschscholzia tincture 1:2 sig:1 tsp QID waking

\section{About the plant eschscholzia californica}

California poppy (Eschscholzia californica) is the official state flower of California since $1903 .{ }^{4}$ The plant, which grows to about $60 \mathrm{~cm}$, has feathery foliage and velvety, golden-orange flower petals. The California poppy is commonly seen blooming in the spring and summer along country roads and freeways throughout much of the state, making this plant a highly recognizable symbol of California, and April 6 of each year is officially designated as California Poppy Day. ${ }^{4}$

It is a member of the Papaveraceae. Older literature stated that it contained small traces of opium, but modern studies don't substantiate that.

It does contain many other isoquinoline alkaloids such as: protopine, cryptopine and $\alpha$-cryptopine, chelerythrine californidine, escholtzine, N-methyllaurotetanine, caryachine, O-methylcaryachine, 6S,12S-neocaryachine, laurotetamine and $\mathrm{N}$-methyl laurotetamine, Chelirubine, chelidonine and homochelidonine. ${ }^{5}$ Which can interact with opioid receptors and ease opium withdrawal and helps pain through GABA and serotonin.

\section{History}

California poppy was a commonly used herb in native American and Hispanic societies, and gained considerable interest from medical practitioners in the late 1800's, when it was added to the Park-Davis drug catalog as "an excellent soporific and analgesic, above all harmless."

"Classic Early American authors/physicians, including HW Felter, contended that unlike morphine and opium poppy derivatives, the use of the whole California poppy plant was nonaddictive, safe, and gentle and offered nonnarcotic pain relief"' ${ }^{6}$

\section{Modern studies}

In mouse trials, Eschscholzia binds to benzodiazepine receptors BDZ and augments GABA's anxiolytic effects and GABA anti nociceptive /inhibitory effect on pain. ${ }^{7}$

In an in vitro study, $70 \%$ ethanol extract of California poppy was 
able to bind to 5-HT(1A) and 5-HT(7) receptors.

The activity on the 5-HT(1A) receptor was at least partly due to the presence of the aporphine alkaloid. ${ }^{5}$

Recent research states, in rodents that the "mild sedative and antinociceptive properties of dry aerial parts of E. californica may be assigned to binding of morphine (and/or other alkaloids) at the $\mu$-opioid receptors. Morphine may be generated in the rodent organism via successive biotransformation of (S)-reticuline present in aerial parts of E. californica. ${ }^{8}$

We are not sure if this occurs in humans?

"One product containing 3 grams of the dried herb standardized to $0.8 \%$ isoquinoline alkaloids (californidine, escholtzine and protopine) is authorized by Health Canada and marketed as an analgesic and mild sedative (hypnotic) to be used as an analgesic or co-analgesic in the management of chronic pain. ${ }^{9}$

Results showed that the standardized extract of California poppy can be used in the management of chronic pain and as a hypnoticmild-sedative for the management of pain-related insomnia. It can be used as a co-analgesic in combination with other pain medications to help reduce the intensity/severity of pain to a tolerable level". ${ }^{10}$

It seems like my strategy has caught on.

A more recent usage for Eschscholzia is in the treatment of heroin addiction and withdrawal. Donna Odierna, herbalist and director of the H.E.A.L.T.H. Needle Exchange clinic in Oakland, California, uses Eschscholzia as the primary ingredient in her clinic's "Kick Juice," along with smaller amounts of Vitex agnus-castus, Avena sativa, Piper methysticum and Verbena officinalis.

Natural medicine never ceases to amaze me!

\section{Acknowledgements}

None.

\section{Conflict of interest}

The author declares no conflict of interest.

\section{References}

1. CDC/NCHS, National Vital Statistics System, Mortality. CDC Wonder, Atlanta, GA: US Department of Health and Human Services, CDC; 2017.

2. Florence CS, Zhou C, Luo F, et al. The Economic Burden of Prescription Opioid Overdose, Abuse, and Dependence in the United States, 2013. Med Care. 2016;54(10):901-906.

3. Fundytus ME. European Journal of Pharmacology. 1996;300(3):173181.

4. https://www.wildlife.ca.gov/Conservation/Plants/California-Poppy

5. Gafner S. Alkaloids from Eschscholzia californica and their capacity to inhibit binding of $[3 \mathrm{H}] 8$-Hydroxy-2-(di-N-propylamino)tetralin to 5-HT1A receptors in Vitro. J Nat Prod. 2006 Mar;69(3):432-435.

6. https://restorativemedicine.org/wp-content/uploads/2017/12/ Escholscholtzia.pdf)

7. Rolland A, et al. Neurophysiological effects of an extract of Eschscholzia californica Cham. (Papaveraceae). Phytother Res. 2001;15(5):377-381.

8. Fedurco M, et al. Modulatory Effects of Eschscholzia californica Alkaloids on Recombinant GABAA Receptors. Biochem Res Int. 2015;2015:617620.

9. https://wildrosecollege.com/encyclopaedia_entry/poppy-californiaeschscholzia-californica/

10. http://www.ema.europa.eu/docs/en_GB/document_library/Herbal_HMPC assessment report/2014/07/WC500170471.pdf 